\title{
Effects of Intensive Phase Antituberculous Therapy on Hepatic and Haematological Parameters in Patients at the University Teaching Hospital in Lusaka, Zambia
}

\author{
Mwaba $G^{1}$, Munkombwe $D^{2}$, Kaonga $P^{3}$, and Mubita $\mathbf{M}^{4}$
}

1. Kabwe General Hospital, Department of Pharmacy, P. O. Box, 80917, Kabwe, Zambia.

2. University of Zambia, School of Health Sciences, Department of Pharmacy, P. O. Box, 50110, Lusaka, Zambia.

3. University Teaching Hospital, Department of Internal Medicine, P. O. Box, 50110, Lusaka, Zambia.

4. University of Namibia, Faculty of Health Sciences, School of Pharmacy, Department of Pharmacy Practice and Policy, P/Bag 13301, Windhoek, Namibia

\author{
Address of Correspondence: \\ Glorious Mwaba, Kabwe General Hospital, Department of Pharmacy, P. O. Box, 80917, Kabwe, Zambia. \\ Telephone: +260977891961; +260963773561; Email: gloriousmwaba@ymail.com
}

\begin{abstract}
Objectives and study design: Zambia is a high tuberculosis burden country. Antituberculous medicines are the mainstay of tuberculosis management. There have been several reports of antituberculous drugrelated haematological and hepatic adverse effects noted in other settings. Adverse events have healthcare cost and morbidity implications. Prevalence and severity of these adverse effects is understudied in patients at University Teaching Hospitals hence the purpose of this study was to identify haematological and hepatic abnormalities and compare parameters before treatment and after completion of intensive phase among the patients. Factors associated with abnormalities were also determined. A prospective longitudinal study was undertaken at Chest Clinic between April 2018 and July 2018. Study patients were followed up for 2 months. Full blood count and liver function tests were recorded at base-line and at follow-up. Abnormalities were defined according to 2017 Department of AIDS Table for Grading the Severity of Adult and Paediatric Adverse Events. Data were analysed using SPSS version 22.0 Paired t-test and Wilcoxon matched - pairs signed rank test were used to compare parameters. Logistic regression was performed to determine factors that were predictive of abnormalities. A $p<0.05$ was considered statistically significant.
\end{abstract}

Results: A total of 37 patients were involved in the study. $56.8 \%$ of patients were male. Mean age of patients was 36.2 years $(19-57$ years $)$ while body mass index was $21.9 \mathrm{~kg} / \mathrm{m} 2$. Only $37.8 \%$ of patients were sputum smear positive at baseline. $56.8 \%$ of patients had HIV co-infection. $45.9 \%$ of patients were on antiretroviral therapy. $45.2 \%$ of patients had grade 1-3 aspartate transaminase derangements at follow-up compared to $29.7 \%$ at baseline. $5.4 \%$ of the patients had grade 1-3 alanine transaminase derangements at baseline while $9.7 \%$ of patients had grade 1 at followup. Fewer patients $(16.1 \%)$ had grade 1-2 anaemia at follow-up while $62.2 \%$ of patients at baseline had grade 1-4 anaemia. More patients (46.2\%) had platelet derangements at follow-up compared to $25.8 \%$ at baseline. Fewer patients had differential white cell count derangements at follow-up compared to baseline. Statistically significant differences in haematological parameters: haemoglobin concentration, haematocrit, red, and white cell, eosinophil and neutrophil counts at baseline and follow-up were found. However, no statistical significant differences in red cell indices were observed. Changes in alanine transaminase levels at baseline and follow-up were statistically significant. Logistic regression was performed to determine the effects of age, gender, body mass index, HIV infection, antiretroviral therapy, sputum smear status, and appropriate baseline full blood count/liver function test parameters on the likelihood of study patients having deranged haemoglobin concentration, white cell count and alanine transaminase at follow-up. Logistic regression models to predict deranged haemoglobin concentration and white cell count were statistically insignificant. None of the predictor variables were associated with likelihood of derangements in alanine transaminase.

Conclusion: Findings of this study show that haematological and hepatic adverse effects were relatively fewer at follow-up and were mostly grades 1-3 in severity. Antituberculous therapy is relatively safe for patients during the initial phase.

Keywords: Adverse effects, antituberculous, haematological, hepatic, initial phase, intensive 


\section{INTRODUCTION}

Inspite of the gradual reduction in the prevalence rate of tuberculosis (TB) since the 1990s ${ }^{[1]}$, one third of the world's population is still known to be infected with tubercle bacilli which can become active disease when conditions are favourable ${ }^{[2,3]}$.

Zambia is amongst the top 30 countries with a high per capita burden of TB, with its prevalence at $319 / 100000$ in individuals aged 15 years and older ${ }^{[3]}$.

First-line antituberculous medicines have been a successful mainstay of the treatment of drugsusceptible tuberculosis. However, these medicines are associated with several adverse effects. Haematological disorders and hepatotoxicity are among the widely reported adverse effects. For instance, Morris et al., reported that haematological and biochemical abnormalities were common among TB patients on antituberculous therapy in Mumbai ${ }^{[4]}$. These adverse effects may cause significant morbidity and compromise treatment regimens ${ }^{[5]}$. They may also lead to use of less active and occasionally more toxic medicines ${ }^{[6,7]}$. Adverse effects can also result in increased treatment costs, hospital visits and hospitalizations ${ }^{[5]}$.

A rise in the liver enzymes such as alanine aminotransferase (ALT), aspartate aminotransferase (AST) and alkaline phosphatase (ALP) are a common adverse effect leading to termination of therapy in patients treated with isoniazid, rifampicin and pyrazinamide ${ }^{[6]}$ When the serum liver enzyme concentration is less than 3 times above the upper limit, the drugs may be continued and patient monitored closely. If the liver enzyme concentration is 3 times above the upper limit and patient has symptoms of hepatotoxicity such as nausea, vomiting and jaundice, the drugs are withdrawn and reintroduced one by one when the liver enzymes revert to normal. The reintroduction starts with the least hepatotoxic drug. If hepatotoxicity recurs after initiation of a particular drug, the drug is permanently withdrawn. However, treatment with less than four drugs may delay time to smear conversion ${ }^{[8]}$.

Some studies have shown that antituberculous drugs induce haematological and hepatic abnormalities [9]. Hepatic abnormalities are amongst the common documented adverse effects

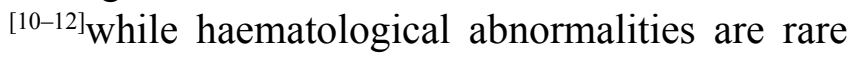
but both are serious adverse effects ${ }^{[13]}$.
There is variation in the reported prevalence of antituberculous therapy - related abnormalities in hepatic and haematological parameters and their associated risk factors. Variation in risk factors has been observed in different races. At the University Teaching Hospitals in Lusaka, there was no data on these adverse effects and the associated risk factors. Consequently, patients at higher risk of developing these abnormalities may not have been identified. Non identification of such patients could lead to poor outcomes of therapy including prolonged hospital stay, morbidity and mortality. Occurrence of adverse effects may lead to, increased healthcare costs, increased default rates and development of resistance to antituberculous therapy.

\section{MATERIALS AND METHODS}

A prospective longitudinal study was done where study subjects were reviewed before commencing antituberculous therapy and at the end of two months. Patients' demographic information such as age, weight and gender were recorded. Venous blood samples were drawn from patients before initiation of the antituberculous medicines for full blood count (FBC) and liver function tests (LFTs) namely ALT and AST. Sputum samples were also obtained for direct microscopy. Patients' sputum smear status along with HIV status and current therapy were recorded.

Thepatients were theninitiated onantituberculosis medicines. After two months, venous blood samples were again collected for FBC and LFTs. Clinical laboratory test results were noted.

The Department of AIDS (DAIDS) (Version 2.1 - March 2017) adverse events grading system shown in table 1was used to grade the severity of the abnormalities ${ }^{[14]}$.

Data were analysed using GraphPad Prism version 8.0.1(GraphPad Software Inc., La Jolla, CA, USA).Continuous variables such age, hepatic and haematological parameters were expressed as mean with standard deviation or median. Categorical parameters such sputum smear status, HIV status, HIV treatment status and gender were expressed as proportions and percentages.

The hepatic and haematological parameters at baseline and follow-up were compared using paired $t$ - tests for normally distributed continuous variables and Wilcoxon matched - pairs signed rank test for non - normally distributed continuous 
variables. Shapiro - Wilk test was used to test for normality of the data distribution. The ROUT (robust regression followed by outlier identification) method was used to detect outliers with Q (maximum desired false discovery rate) set to 1 per cent. Significant outliers were excluded from the data set and the results of the analyses of data without outliers were also reported. Binary logistics regression was performed using SPSS version 22.0 (IBM Corp., Armonk, NY, USA) to determine the effects of age, gender, BMI, HIV infection, ART, sputum smear status, and appropriate baseline FBC/LFT parameters on the likelihood of study patients having deranged $\mathrm{Hb}$, WCC and ALT at follow-up. A p value $<0.05$ was considered statistically significant.

\section{MAIN STUDY FINDINGS}

A total of 37 patients were included in this study. 21 (56.8 percent) patients were male. The mean age of the patients was 36.2 years (19 - 57 years) while their mean BMI was $21.9 \mathrm{~kg} / \mathrm{m} 2(17-29.3 \mathrm{~kg} /$ $\mathrm{m} 2$ ). Only 14 (37.8 percent) patients were sputum smear positive at baseline. $21(56.8 \%)$ patients had HIV co-infection. Only 17 (45.9 percent) patients were on ART.

Increase in the proportion of patients with elevated ALT (grades 1 - 3) was noted, the number at baseline was $2(5.4 \%)$ and $6(16.2 \%)$ at follow - up the elevation was statistically significant $(p=0.025)$. There was also an increase in the proportion of patients with raised AST (grades 13 ) at follow- up. The values being $11(29.7 \%)$ at baseline and $15(40.5 \%)$ at follow, however, the increase was not statistically significant $(\mathrm{p}=0.895)$. More patients had anaemia and leukopenia (grade 1 - 4) before drug therapy $23(62.2 \%)$ and $2(5.4 \%)$ respectively compared to follow - up 5(13.5\%) and $0 \%$ respectively. The raise in haemoglobin concentration and decrease in white cell count were statistically significant $(\mathrm{p}<0.0001$ and $\mathrm{p}=$ 0.006 respectively). The proportion of patients with thrombocytopenia increased at follow - up 6 $(16.2 \%)$ at baseline and $13(35.1 \%)$ at follow - up, however, the decrease in platelet count was not statistically significant $(p=0.127)$.

Age, sex, baseline hepatic and haematological parameters and BMI were not found to be associated with hepatic or haematological abnormalities.

\section{DISCUSSION}

The study showed that the majority of TB patients were young adults with a mean age of 36.2 years and age range of 19 - 57 years signifying the most productive population. This is similar to the findings by Bashir et al. and Kassa et al. whose studies included patients with mean age of 33 and 34.8 years, respectively ${ }^{[(9,15]}$. Yaranal et al. undertook a study in patients with a mean age of 41 years ${ }^{[16]}$. The reasons for the higher prevalence of TB in the young adult age group could be due to HIV infection, a known immunosuppressant which is also more prevalent in this age group ${ }^{[17]}$. In addition, younger adults could be exposed to other factors that might predispose them to TB infection such as tobacco smoke and overcrowded environments.

Most of the patients were males accounting for 56.8 percent. A similar finding has been reported by several other studies ${ }^{[15,16,18,19]}$. The findings of the present study are, however, different from those described by Marra et al. who included an equal number of male and female patients in their study ${ }^{[20]}$. The findings of the present study with respect to gender distribution are also similar to those reported by the Zambia TB prevalence survey which found more males with tuberculosis ${ }^{[17]}$. The similarity of the findings could be due to the fact that globally, more men have TB ${ }^{[21]}$.Nhamoyebonde and Leslie contend that the relationship between male sex and tuberculosis risk is less clear and is likely to involve a highly complex network of factors ${ }^{[21]}$. The differences in the findings may be because the degree of male bias varies by geographic location and by year, however, the overall trend is clear, and of the 20 high-burden countries for which data are available, more males have been recorded to have TB ${ }^{[21]}$.

A large number of the patients (56.8 percent) had HIV co - infection as highlighted by the Zambia TB prevalence survey. This could be due to lowered immune function among HIV patients which leads to activation of latent tuberculosis as HIV infection causes suppressed cell - mediated immunity ${ }^{[22]}$. The majority of patients (62.2 percent) had sputum smear negative tuberculosis. Montales et al. explain that HIV co-infection may alter the pathogenesis of tuberculosis and lead to negative sputum smear results ${ }^{[23]}$. 
Tuberculosis generally presents with constitutional signs and symptoms such as cough which may be dry initially then productive later, night sweats, loss of appetite and weight loss. Therefore, it is anticipated that TB patients may have lower BMIs. The present study found that patients' BMI ranged from $17 \mathrm{Kg} / \mathrm{m} 2$ to $29.3 \mathrm{Kg} / \mathrm{m} 2$ with a mean BMI of $21.9 \mathrm{Kg} / \mathrm{m} 2$.These findings are similar to those reported by Abera et al. who found a mean BMI of $20.6 \mathrm{Kg} / \mathrm{m} 2$ with a range of $17.08 \mathrm{Kg} / \mathrm{m} 2$ to $24.06 \mathrm{Kg} / \mathrm{m} 2{ }^{[12]}$. The results of the present study, however, are in contrast to those found by Hassen Ali et al. and Nagu et al. where the majority of the patients ( 81.8 percent and 51 percent, respectively) had BMI less than $18.5 \mathrm{Kg} / \mathrm{m} 2{ }^{[11,24]}$.

In the present study, more patients had elevated ALT and AST levels at follow -up (Table ). These findings are different from those highlighted by Hassen Ali et al and Shang et al. ${ }^{[1,25]}$. In these two studies, only patients with normal baseline ALT and AST levels were enrolled. Hassen Ali et al found that $61.5 \%$ of the patients had elevated ALT at follow -up and 11.1\% had elevated AST(11) and Shang et al. found $4.73 \%$ had elevated ALT at follow - up and $1.3 \%$ had elevated AST respectively[25]. The difference in the findings could be due to the fact that the study undertaken by Hassen Ali et al. had a larger sample size. Shang et al., found that the proportion of patients with elevated ALT was lower than that of the present study ${ }^{[25]}$. This could be because of differences in the metabolism of isoniazid as slow metabolizers are prone to hepatic abnormalities and fast metabolizers are less prone ${ }^{[26]}$.

The findings of the present study show a decrease in the proportion of patients with anaemia at follow - up (13.5 percent) compared to 62.2 percent at baseline. This is in contrast with the findings of Enoh et al.and Kassa et al.who found that 37.1 percent and 72 percent of patients had anaemia at follow-up, respectively ${ }^{[9,19]}$. The differences in the findings could be due to differences in patients' genetic predisposition to adverse effects due to variable metabolism of antituberculous drugs in the different settings. Patients' anaemia in the current study improved as they may have had anaemia of chronic illness which improved as the infection resolved ${ }^{[15]}$.In the studies conducted by Enoh et al. and Kassa et al. the increase in the proportion of patients with anaemia at follow - up was attributed to the adverse effect of antituberculous drugs.
The present study did not find any association between age, gender, HIV status, HIV treatment status, BMI, sputum smear status and baseline ALT with the increase in ALT level at follow- up. These findings are similar to those reported byAbera et al. who found that age, gender and nutritional status were not associated with elevated liver enzymes ${ }^{[12]}$. The findings of the present study were, however, different from the findings of numerous other studies which found that age above 60 years was associated with increase in the ALT levels ${ }^{[5,6,20,27]}$, although none of the patients in the current study was above 60 years old. Marra et al. also found that higher baseline ALT levels were associated with elevated ALT levels at follow - up ${ }^{[20]}$. Hassen Ali et al. established that lower BMI was a predictor of elevated ALT levels ${ }^{[11]}$ whereas An et al. stated that female sex was associated with deranged ALT levels ${ }^{[10]}$. The differences in the findings of the present study and those of the other studies could be due to the fact that the oldest patient in the study was 57 years and as a consequence, none of the patients were above 60 years.

Although it isexpected that the findingsof the presentstudy would be similar to those reported by otherstudies undertaken among African patients, who are generally considered slow acetylators of isoniazid and prone to developing isoniazid induced hepatotoxicity which is characterised by raised liver enzymes ${ }^{[26]}$, the findings of this study were contrary to this assertion.

The differences in the findings were probably due to the use of different study designs, however, the results of the current study would be expected to be similar to those found by Ekhabbazi et al. who carried out a prospective longitudinal study[28] like the present study but they found that age, gender, HIV status and baseline transaminase level were associated withelevated liver enzymes. The findings of a cohort study undertaken byAbera et al. in Ethiopia ${ }^{[12]}$ were similar to those of the present study.

Regarding limitations of the study, one patient was lost to follow hence there was missing data which was not included in the data analysis. Data analysis was only carried out on complete paired data.

The researcher had no control on influence of other drugs taken by patients during follow-up which might affect hepatic and haematological parameters including other unidentified confounders. 
The effects of individual antituberculous drugs on hepatic and haematological parameters were not explored.

\section{CONCLUSION}

The use of intensive phase antituberculous drugs was associated with haematological abnormalities such as anaemia (grade 1-3), leukocytosis and thrombocytopenia (grade 1-3) and elevation in ALT and AST levels. Statistically significant differences in haemoglobin concentration $(\mathrm{p}<0.0001)$, white cell count $(p=0.006)$ and ALT level $(p=0.025)$ were observed. However, the proportion of patients with derangements in haemoglobin level and white cell count decreased at follow - up. Factors such as age, gender, BMI, HIV infection, ART, sputum smear status, and appropriate baseline FBC/LFT parameters did not predict the likelihood of ALT derangements at follow-up. Based on the findings of this study, antituberculous drugs are safe for use in Zambian patients however, close monitoring is required for patients with initial mild elevation in liver enzymes.

\section{ACKNOWLEDGEMENT}

The authors would like to thank the staff at the Chest Clinic and Clinical Chemistry Laboratory of the University Teaching Hospital in Lusaka.

\section{REFERENCES}

1. Glaziou P, Raviglione M, Falzon D, Floyd K. Global epidemiology of tuberculosis. Cold Spring Harb Perspect Med. 2015;5(a017798):7.

2. World Health Organization. Global tuberculosis report 2016. Geneva; 2016.

3. World Health Organization. End TB global tuberculosis report 2017. Geneva; 2017.

4. Morris DWC, Bird RA, Nell H. The haematological and biochemical changes in severe pulmonary tuberculosis. Q J Med. 1990;73(272):1151-9.

5. Yee D, Valiquette C, Pelletier M, Parisien I, Rocher I, Menzies D. Incidence of serious side effects from first-line antituberculosis drugs among patients treated for active tuberculosis. Am J RespirCrit Care Med. 2003;167:1472-7.
6. Schaberg T, Rebhan K, Lode H. Risk factors for side-effects of isoniazid, rifampin and pyrazinamide in patients hospitalized for pulmonary tuberculosis. EurRespir J. 1996;9(10):2026-30.

7. Lv X, Tang S, Xia Y, Wang X, Yuan Y, Hu $\mathrm{D}$, et al. Adverse reactions due to directly observed treatment strategy therapy in Chinese tuberculosis patients: A prospective study. PLoS One. 2013;8(6):1-8.

8. Long R, Bochar K, Chomyc S, Talbot J, Barrie J, Kunimoto D, et al. Relative versus absolute noncontagiousness of respiratory tuberculosis on treatment. Infect Control HospEpidemiol. 2003;24(11):831-8.

9. Kassa E, Enawgaw B, Gelaw A, Gelaw B. Effect of anti-tuberculosis drugs on hematological profiles of tuberculosis patients attending at University of Gondar Hospital, Northwest Ethiopia. BMC Hematol. 2016;16(1):1-11.

10. An $\mathrm{H}, \mathrm{Wu} \mathrm{X}$, Wang $\mathrm{Z}, \mathrm{Xu} J$, Zheng $\mathrm{S}$, Wang $K$. The clinical characteristics of antituberculosis drug induced liver injury in 2457 hospitalized patients with tuberculosis in China. African J Pharm Pharmacol. 2013;7(13):710-4.

11. Hassen Ali A, Belachew T, Yami A, Ayen WY. Anti-tuberculosis drug induced hepatotoxicity among TB/HIV co-infected patients at Jimma University Hospital, Ethiopia: Nested casecontrol study. PLoS One. 2013;8(5):1-8.

12. Abera W, Cheneke W, Abebe G. Incidence of antituberculosis-drug-induced hepatotoxicity and associated risk factors among tuberculosis patients in Dawro Zone, South Ethiopia: A cohort study. Int $\mathrm{J}$ Mycobacteriology. 2016;5(1):14-20.

13. Farazi A, Sofian M, Jabbariasl M, Keshavarz S. Adverse reactions to antituberculosis drugs in Iranian tuberculosis patients. Tuberc Res Treat. 2014;2014:1-6.

14. Division of AIDS. Division of AIDS (DAIDS) table for grading the severity of adult and pediatric adverse events. DAIDS AE Grading Table Version 2.1-March 2017. 2017.

15. Bashir BA, Abdallah SA, Mohamedani AA. Anemia among patients with pulmonary tuberculosis in Port Sudan, Eastern Sudan. Int J Recent Sci Res. 2015;6(5):4128-31. 
16. Yaranal PJ, Umashankar T, Govindareddy S. Hematological profile in pulmonary tuberculosis. Int $\mathbf{J}$ Heal Rehabil Serv. 2013;2(1):50-5.

17. Kapata N, Chanda-Kapata P, Ngosa W, Metitiri M, Klinkenberg E, Kalisvaart N, et al. The prevalence of tuberculosis in Zambia: Results from the first national TB prevalence survey, 2013-2014. PLoS One. 2016;11(1):1-14.

18. Koju D, Rao SB, Shrestha B, Shakya R, Makaju R. Occurrence of side effects from anti - tuberculosis drugs in urban Nepalese population under DOTS treatment. KathanduUnivJounalSci Technol. 2005;1(1):1-4.

19. Enoh JE, Pokam BDT, Eyo AO, Okafor IM, Nguedia CA, Fominyam BT, et al. Drug induced hematological disorders in patients on antituberculosis drugs in the South West Region of Cameroon. Eur J Pharm Med Res. 2017;4(1):155-61.

20. Marra F, Marra CA, Bruchet N, Richardson K, Moadebi S, Elwood RK, et al. Adverse drug reactions associated with first-line antituberculosis drug regimens. Int J Tuberc Lung Dis. 2007;11(8):868-75.

21. Nhamoyebonde S, Leslie A. Biological differences between the sexes and susceptibility to tuberculosis. J Infect Dis. 2014;209 (S3):S100-6.

22. Getahun $\mathrm{H}$, Chaisson RE, Raviglione $\mathbf{M}$. Latent mycobacterium tuberculosis infection: Reply. N Engl J Med. 2015;373(12):1179-80.
23. Montales MT, Beebe A, Chaudhury A, Patil N. Mycobacterium tuberculosis infection in a HIV-positive patient. Respir Med Case Reports. 2015;16:160-2.

24. Nagu TJ, Spiegelman D, Hertzmark E, Aboud S, Makani J, Matee MI, et al. Anemia at the initiation of tuberculosis therapy is associated with delayed sputum conversion among pulmonary tuberculosis patients in Dar-esSalaam, Tanzania. PLoS One. 2014;9(3):1-8.

25. Shang P, Xia Y, Liu F, Wang X, Yuan Y, $\mathrm{Hu} \mathrm{D}$, et al. Incidence, clinical features and impact on anti-tuberculosis treatment of antituberculosis drug induced liver injury (ATLI) in China. PLoS One. 2011;6(7):1-7.

26. Gonzalez F, Coughtrie M, Tukey R. Drug Metabolism. In: Brunton L, Hilal-Dandan R, Knollmann B, editors. Goodman \& Gilman's Pharmacological Basis of Therapeutics. 13th ed. New York: McGraw-Hill; 2018. p. 85100.

27. Pande JN, Singh SP, Khilnani GC, Khilnani S, Tandon RK. Risk factors for hepatotoxicity from antituberculosis drugs: A case-control study. Thorax. 1996;51(2):132-6.

28. Ekhabbazi H, Benkirane R, Khadmaoui A, Sefiani H, Quyou A, Mokhtari A, et al. Evaluation of adverse effects of antituberculosis in El-IdrissiHospital, Kenitra, Morocco. IOSR J Pharm. 2015;5(1):6-11. 


\section{TABLES AND FIGURES}

Tables

Table 1: The 2017 DAIDS Table for Grading the Severity of Adult and Paediatric Adverse Events

\begin{tabular}{|l|l|l|l|l|}
\hline \multicolumn{1}{|c|}{ Parameter } & \multicolumn{1}{|c|}{$\begin{array}{c}\text { Grade 1 } \\
\text { Mild }\end{array}$} & \multicolumn{1}{c|}{$\begin{array}{c}\text { Grade 2 } \\
\text { Moderate }\end{array}$} & $\begin{array}{c}\text { Grade 4 Potentially } \\
\text { Life-Threatening }\end{array}$ \\
\hline ALT/AST, High & 1.25 to $<2.5 \times$ ULN & 2.5 to $<5.0 \times$ ULN & 5.0 to $<10.0 \times$ ULN & 7.0 to $<9.0$ \\
\hline $\begin{array}{l}\text { Hemoglobin, Low (g/dL) } \\
\geq 13 \text { years of age (male only) }\end{array}$ & 10.0 to 10.9 & 9.0 to $<10.0$ & 6.5 to $<8.5$ \\
\hline$\geq 13$ years of age (female only) & 9.5 to 10.4 & 8.5 to $<9.5$ & $1.000 \times 10^{9}$ to $1.499 \times 10^{9}$ & $<1.000 \times 10^{9}$ \\
\hline $\begin{array}{l}\text { WBC, Decreased } \\
\text { cells/L) } \\
>7 \text { days of age }\end{array}$ & $2.000 \times 10^{9}$ to $2.499 \times 10^{9}$ & $1.500 \times 10^{9}$ to $1.999 \times 10^{9}$ & $<.0$ \\
\hline Platelets, Decreased (cells/L) & $100 \times 10^{9}$ to $<125 \times 10^{9}$ & $50 \times 10^{9}$ to $<100 \times 10^{9}$ & $25 \times 10^{9}$ to $<50 \times 10^{9}$ & $<25 \times 10^{9}$ \\
\hline
\end{tabular}

Table 2: Summary of patient demographics.

\begin{tabular}{|l|l|}
\hline Gender & N (\%) \\
\hline Male & $21(56.8)$ \\
\hline Female & $16(43.2)$ \\
\hline Sputum smear status at baseline & $14(37.8)$ \\
\hline Positive & $23(62.3)$ \\
\hline Negative & $21(56.8)$ \\
\hline HIV status & $16(43.2)$ \\
\hline Positive & \\
\hline Negative & $20(54.1)$ \\
\hline HIV treatment status & $17(45.9)$ \\
\hline On ART &
\end{tabular}

Table 3: Haematological and hepatic abnormalities among patients

\begin{tabular}{|l|l|l|}
\hline Parameter (grade) & Baselinen (\%) & Follow-upn (\%) \\
\hline Normal ALT level & $35(94.6 \%)$ & $31(83.8 \%)$ \\
\hline Increase in ALT level (grade 1- 3) & $2(5.4 \%)$ & $6(16.2 \%)$ \\
\hline Normal AST level & $26(70.3 \%)$ & $22(59.5 \%)$ \\
\hline Increase in AST level (grade 1-3) & $11(29.7 \%)$ & $15(40.5 \%)$ \\
\hline Normal Hb level & $14(37.8 \%)$ & $32(86.5 \%)$ \\
\hline Anaemia (grade 1-4) & $23(62.2 \%)$ & $5(13.5 \%)$ \\
\hline Normal Platelet count & $21(56.8 \%)$ & $24(64.9 \%)$ \\
\hline Thrombocytopenia (grade 1-4) & $6(16.2 \%)$ & $13(35.1 \%)$ \\
\hline Thrombocytosis & $10(27 \%)$ & $0(0 \%)$ \\
\hline Normal white cell count & $29(78.4 \%)$ & $36(97.3 \%)$ \\
\hline Leukopenia (grade 1 -4) & $2(5.4 \%)$ & $0(0 \%)$ \\
\hline Leukocytosis & $6(16.2 \%)$ & $1(2.7 \%)$ \\
\hline
\end{tabular}


Table 4a: Differences in haematological parameters among patients at baseline and follow-up (paired samples t-tests)

\begin{tabular}{|l|c|c|c|c|c|}
\hline \multicolumn{1}{|c|}{ Parameter } & No. of pairs & $\begin{array}{c}\text { Baseline } \\
\text { Mean (SD) }\end{array}$ & $\begin{array}{c}\text { Follow-up } \\
\text { Mean (SD) }\end{array}$ & t (95\% CI) & P value \\
\hline Haemoglobin concentration (g/dl) & 37 & $9.51(3.25)$ & $12.37(1.67)$ & $\begin{array}{c}-5.59 \\
(-3.89--1.83)\end{array}$ & $<0.0001$ \\
\hline $\begin{array}{l}\text { Platelet count } \\
\text { (x 109/L ) }\end{array}$ & 37 & 309.17 & 255.79 & $\begin{array}{c}1.562 \\
(-13.78- \\
(125.89)\end{array}$ & 0.127 \\
\hline $\begin{array}{l}\text { White cell count } \\
\text { (x 109/L ) }\end{array}$ & 37 & $7.26(3.53)$ & $5.33(1.89)$ & $\begin{array}{c}2.93 \\
(0.60-3.27)\end{array}$ & 0.006 \\
\hline
\end{tabular}

Table 3b: Differences in hepatic parameters among patients at baseline and follow-up (Wilcoxon signed rank test)

\begin{tabular}{|c|c|c|c|c|c|}
\hline $\begin{array}{c}\text { Parameter } \\
\text { (units) }\end{array}$ & $\begin{array}{c}\text { No. of } \\
\text { pairs }\end{array}$ & $\begin{array}{c}\text { Baseline } \\
\text { Median }\end{array}$ & $\begin{array}{c}\text { Follow-up } \\
\text { Median }\end{array}$ & Z & P value \\
\hline ALT level (IU/L) & 37 & 18.4 & 26.7 & -2.225 & 0.025 \\
\hline AST level (IU/L) & 37 & 34.5 & 35.0 & -1.075 & 0.896 \\
\hline
\end{tabular}

